\title{
Defining a General Collective Intelligence Based Renewable Energy Solution Development Program
}

\author{
Andy E. Williams ${ }^{1, *}$ \\ ${ }^{1}$ Nobeah Foundation, Nairobi, Kenya
}

\begin{abstract}
The choice of which problem renewable energy programs target is one that might benefit from greater General Collective Intelligence or GCI. Where a collective intelligence uses the intelligence of crowds to maximize impact on a given problem, a GCI is defined as having the capacity for general problem solving ability, and therefore the capacity to increase outcomes by choosing the optimal problem to solve. Collectively intelligent development aims to solve the problems required to create the ability for groups to reliably explore all of the currently possible solution space and to reliably converge on the best available solution in that space, so that developing solutions which facilitate a significantly improved impact on targeted outcomes as compared to other development processes is reliably achievable. Where conventional development processes have known cognitive or other biases that may prevent certain categories of solutions from being selected by groups even where optimal, collectively intelligent development aims to create the capacity to reliably converge on the optimal overall solution. A proposed Collective Intelligence Based Renewable Energy Program aims to leverage human-centric functional modeling to provide groups with a common model of the problem being solved. This proposed program then leverages a newly developed model of General Collective Intelligence to collectively reason in terms of those common functional models as required to develop a solution that optimizes impact on the targeted problem, such as the problem of achieving a significantly lower cost of access to sustainable renewable energy, or achieving a significant increase in environmental sustainability of that renewable energy, as defined by metrics that might be related to carbon emissions.
\end{abstract}

Keywords: General Collective Intelligence, Human-Centric Functional Modelling, renewable energy

\section{Background}

This paper explores how a proposed Collective Intelligence Based Renewable Energy Program leverages human-centric functional modeling and collectively intelligent cooperation in it's plan to develop a renewable energy solution that might reliably achieve a significantly lower cost of access to sustainable renewable energy, and therefore significantly accelerate achievement of carbon emission reduction targets through increasing deployment of clean renewable energy. This paper also explores how the collectively intelligent combination of all potential interventions has the potential to make a far bigger impact on greenhouse gas emissions than any one intervention alone, including carbon taxes.

\section{Introduction}

Collectively intelligent development aims to create the ability to reliably explore a much larger region of the currently available solution space and to reliably select the best available solution in that space so that developing solutions which facilitate a significantly improved impact on targeted outcomes as compared to other 
development processes is reliably achievable. Where conventional development has known cognitive or other biases that may prevent certain categories of solutions from being selected even where optimal, collectively intelligent design and development aims to create the capacity to methodically compare all known candidates for all known components of that solution and to select the best for each, so that development reliably converges on the optimal overall solution.

This collective intelligence approach involves defining common models of the problems to be solved by the group, as well as of potential solutions for the group, through a Human-Centric Functional Modeling (HCFM) [1] approach rather than through an approach based on any assumed implementation of the solution. It also involves following principles of decentralized cooperation that ensure solutions are aligned with maximizing impact on the collective problem (in this case potentially carbon emissions) rather than following centralized processes that align decision-making with the interests of a subset of decision-makers. This program also defines patterns of collectively intelligent cooperation designed to increase outcomes for all stakeholders. For investors this means increasing projected returns above market averages at decreased risk, so that raising the required investment is reliably achievable. For donors this means increasing impact per dollar of program funds to the point that donor support is reliably achievable. For governments this means increasing incentives until government participation is reliably achievable. Similar benefits are designed for renewable energy entrepreneurs, as well as for services providers, whether for-profit or non-profit. Through this approach, as well as through defining universal metrics of fitness of each proposed solution component in achieving these functions, the barriers preventing a larger number of solution providers from cooperating to provide a solution are intended to be removed, so that selection from a large range of components can reliably converge on the best possible composite solution.
Facilitating massively collaborative development is just one of innumerable ways that collective intelligence has the potential to greatly increase capacity to deploy clean renewable energy solutions and to reduce carbon emissions. This program aims to deploy a collective intelligence based renewable energy solution in the more green field environment of the Caribbean, so the solution may be modified and reapplied in Collective Intelligence Based Renewable Energy Programs in Europe, and in America, to create the potential to greatly increase capacity to deploy renewable energy and to reduce carbon emissions in those additional geographies as well.

\section{Related Work}

Though others have described the concept of a general collective intelligence factor (c factor) [2], though at least one other has defined a model for a general collective intelligence factor [3], and though others have described the concept of a collective super intelligence [4], to the author's knowledge the author's own work is the only model that defines the specific mechanisms required for a General Collective Intelligence or GCI with the potential for exponentially greater general problem-solving ability (intelligence) than any individual [5], [6]. Because of this, and because this model is so new, all of the existing literature surrounding GCI refers to the author's own published work, or pre-prints of the author's unpublished work that are still under review.

\section{Purpose, Research Questions, and Approach}

The business life-cycle of any product or service, including renewable energy solutions, spans design, development, marketing, sales, and every other process up to recycling. The purpose of this paper was to demonstrate that using functional modeling to decompose renewable energy solutions into common functional components, and using General Collective Intelligence to adaptively problem solve through the entire business life-cycle of renewable energy solutions using any implementation of those functional components available anywhere, can be used to significantly increase any outcome targeted by 
renewable energy programs, such as access to affordable renewable energy, or reduction of greenhouse gas emissions, as compared to any outcome reliably achievable by any other means.

The research questions addressed in this paper and the method with which they were approached are described below:

Section 4: Research Question Addressed

4.1. What uncertainty is there in which outcomes should be optimally targeted by renewable energy programs?

4.2. What measures might be used to manage uncertainty in which outcomes should be optimally targeted by renewable energy programs?

4.3. Can decomposing renewable energy solutions into common functional components, and using General Collective Intelligence to adaptively problem solve through the entire business lifecycle of renewable energy solutions be used to manage this uncertainty while significantly increasing any outcome targeted by renewable energy programs?

\section{Section 5: Model}

5.1. General Collective Intelligence and the Development of Clean Renewable Energy Solutions.

5.2. General Collective Intelligence as an Essential Component of Sustainability

Section 6. Method

6.1. Define a generalized renewable energy program and assess the uncertainty in its parameters.

6.2. Define some types of renewable energy program outcomes related to uncertainty that can't currently be addressed. Define mechanisms by which they might be.

6.3. This functional decomposition and use of GCI to increase general problem-solving ability, has been suggested in other topics to increase capacity to solve the problem of achieving targeted outcomes. An analysis is performed to assess whether and how the same methodology might be applied to renewable energy.
Section 7. Findings

Section 8. Research Limitations

Section 9. Practical Implications

Section 10. Conclusions

\section{Model}

Aspects of the model of collective cognition that are relevant to the research questions are described below.

\subsection{General Collective Intelligence and the Development of Clean Renewable Energy Solutions}

This paper suggests that General Collective Intelligence might be required for the design and development process of any product or service to have the capacity to develop optimal solutions, because GCI is required to reliably remove constraints that tend to prevent groups from developing entire categories of solutions [7]. Two categories of solutions this paper suggests can't be reliably developed without collective intelligence are those solutions requiring massive resources to be directed in ways other than those dictated by the large stakeholders able to afford those costs on their own, and those solutions requiring massive collaboration to be directed towards ideas other than those with popular mind share. Many other categories of solutions that are constrained against being selected by group development processes without GCI might exist.

\subsection{General Collective Intelligence as an Essential Component of Sustainability}

Other work [8] has suggested that without GCI, systemic technology related forces drive technology to become aligned with centralized interests rather than with maximizing collective outcomes in any area such as renewable energy. The rationale behind this argument is that technology removes the limits to centralization and inequality in groups, with the result that organizations might never be allowed to stop competing to unsustainably increase consumption 
to acquire further resources, without the threat of being eliminated from the marketplace.

If so, this is suggested to not only potentially force for-profit organizations to compete to unsustainably increase the consumption of their customers; but also to force non-profit organizations to compete for donations, rather than incentivizing cooperation to maximize any collective maximize impact. GCI on the other hand aims to decentralizes processes so that collective outcomes can be maximized for all who cooperate to achieve a common goal, creating sufficient mutual benefit in cooperating for this cooperation to be stable. At the same time GCI aims to balance this decentralization with centralization that prioritizes the functions with the greatest impact so that overall outcomes can be maximized.

Take consumer electronics as an example of the potential impact of GCI. Assume that over the last two years a consumer bought at least half a dozen headsets for conference calls, as they kept breaking. Each time the consumer would have had to discard the entire headset even though only one part was broken, because the headset was essentially designed as one piece. If the headset were designed so that the jack was separate, the cord was separate, the speakers were separate, and all the other pieces were separate, and all of those parts were "human-centric" in being replaceable by the user without any specialized tools or expertise, the consumer would have been able to replace just that one part. Rather than lasting for a few months, the headphones instead might last 20 years. This value proposition could provide those headphones with an unbeatable competitive advantage to consumers. But no current business could survive by planning to sell no more than one set of headphones to each customer during the customer's lifetime.

However where the value of adding each new participate to a chain of cooperation is greater than zero, GCI might be used to remove the barriers to scaling cooperation so the value of that cooperation can be increased as much as needed to reliably create unbeatable competitive advantage for those businesses that cooperate towards the common good, in this case cooperating to reduce consumption. If it were possible to search for every opportunity for every business to gain from doing so, it might be possible to form entire value chains that cooperate to share designs so they could reuse the same part between them. With this approach the total cost of the sustainable headset might be lowered, and the market share might be raised, to the point where a business could quite comfortably sell only one headset per lifetime. The cooperation in such intelligent value chains might use part of the value created by each participant's cooperation in order to incentivize their participation so that the cooperation always creates more value than it costs, thereby ensuring these chains of cooperation naturally converge on increasing sustainability. Collective intelligence based development is in part a methodology to help identify opportunities to cooperate to develop solutions comprised of such modules.

Using a collective intelligence approach in design [9], it might be possible to design entire value chains that gain powerful competitive advantage from cooperating to decrease consumption, and cooperating to maximize collective well-being in other ways through maximizing social, economic, and other impacts. This might be achieved both by using GCI to select the optimal problem to solve, and by using GCI to optimize collective outcomes by individually customizing every product or services so that it maximizes outcomes for each individual [10]. And because of this competitive advantage, such businesses and their impacts might potentially spread virally, without the need for any laws or policies to support them. The ten phases of the proposed Collective Intelligence based Program to Accelerate Achievement of the Sustainable Development Goals (CIPAA-SDGs) have attempted to do exactly this [11].

\section{Method}

The research question was addressed using the methods summarized in table 2 . 
Table 1. Methods.

\begin{tabular}{|c|c|}
\hline Research Question & Method \\
\hline $\begin{array}{l}\text { 1. What uncertainty } \\
\text { is there in which } \\
\text { outcomes should be } \\
\text { optimally targeted } \\
\text { by renewable energy } \\
\text { programs? }\end{array}$ & $\begin{array}{l}\text { 1. Define a } \\
\text { generalized } \\
\text { renewable energy } \\
\text { program and assess } \\
\text { the uncertainty in its } \\
\text { parameters. }\end{array}$ \\
\hline $\begin{array}{l}2 . \text { What measures } \\
\text { might be used to } \\
\text { manage uncertainty } \\
\text { in which outcomes } \\
\text { should be optimally } \\
\text { targeted by } \\
\text { renewable energy } \\
\text { programs? }\end{array}$ & $\begin{array}{l}\text { 2. Define some types } \\
\text { of renewable energy } \\
\text { program outcomes } \\
\text { related to uncertainty } \\
\text { that can't currently } \\
\text { be addressed. Define } \\
\text { mechanisms by } \\
\text { which they might be. }\end{array}$ \\
\hline $\begin{array}{l}\text { 3. Can decomposing } \\
\text { renewable energy } \\
\text { solutions into } \\
\text { common functional } \\
\text { components, and } \\
\text { using General } \\
\text { Collective } \\
\text { Intelligence to } \\
\text { adaptively problem } \\
\text { solve through the } \\
\text { entire business life- } \\
\text { cycle of renewable } \\
\text { energy solutions be } \\
\text { used to manage this } \\
\text { uncertainty while } \\
\text { significantly } \\
\text { increasing any } \\
\text { outcome targeted by } \\
\text { renewable energy } \\
\text { programs? }\end{array}$ & $\begin{array}{l}\text { 3. This functional } \\
\text { decomposition and } \\
\text { use of GCI to } \\
\text { increase general } \\
\text { problem-solving } \\
\text { ability, has been } \\
\text { suggested in other } \\
\text { topics to increase } \\
\text { capacity to solve the } \\
\text { problem of achieving } \\
\text { targeted outcomes. } \\
\text { An analysis is } \\
\text { performed to assess } \\
\text { whether and how the } \\
\text { same methodology } \\
\text { might be applied to } \\
\text { renewable energy. }\end{array}$ \\
\hline
\end{tabular}

\subsection{Uncertainty in Renewable Energy Development Programs}

If a renewable energy research and development program assumes what the optimal solutions are, then there might not appear to be any uncertainty. But if there are no questions, there is no opportunity to apply an adaptive problem-solving process such as GCI in order to significantly increase outcomes.

There are a great many sources of uncertainty. Assume for example, that the energy needs of tomorrow have already been solved by a small modular power source able to provide a constant but far greater (potentially limitless) amount of clean electricity. Or assume that this small modular power source able to provide a finite output of clean energy that can be adjusted up or down. From Thorium reactors, to cheaper and more efficient solar, geothermal or other technologies, the potential sources of such disruptive innovation are hard to predict. But what can very reliably be predicted is that technology disruption will come. This potential for disruption is a source of uncertainty.

When disruption does come it might have wide ranging implications on the energy grid. What would the energy grid look like if that energy source had a fixed power output? What would the energy grid look like if that energy source had an adjustable power output? What would the energy grid look like if that energy source were the size of a car? What would the energy grid look like if that energy source were the size of a watch battery and could be incorporated into every electronic device? What would the energy grid look like if these power sources cost as much as a small town? What would the energy grid look like if these power sources cost as little as a grain of rice?

The uncertainties in renewable energy development research programs then potentially include all the attributes of the optimal power source, since that power source is not yet known.

\subsection{Managing Uncertainty in Renewable Energy Development Programs}

Uncertainty can have great impact in renewable energy research and development programs. If the probability of successful cooperation decreases with the number of participants, projects requiring massive resources might only be reliably funded if they are aligned with the policies of some large 
organization capable of funding such projects alone. The policies determining what such large organizations can fund might be slow moving and bureaucratic. Therefore large solutions that decide to remain open to quickly shifting to any approach that maximizes outcomes, rather than being closed to approaches other than those allowed by those slow moving policies, might not be reliably achievable under current approaches.

However, aligning the interests of large groups so that orchestration of massive collaboration is possible, might allow solutions to be implemented with a small amount of resources from each of a very large number of participants, as opposed to implementing solutions with a large amount of resources from a very small number of participants. Both large projects funded by only a few participants and that are bound by the bureaucratic policies of large organizations, and large projects funded by a large number of participants through leveraging massive collaboration, are therefore categories of problems that may be critically important in developing clean renewable energy sources.

\subsection{Increasing Renewable Energy Program}

Outcomes with Functional Modeling and General Collective Intelligence

On starting asking these questions it becomes clear that it makes sense to develop solutions that are smart enough to be flexible. And it makes sense to understand how current design and development processes limit such flexibility. Through understanding the limitations of current processes, it might become possible to evolve a development process that makes development of such flexible solutions reliably achievable. Applied intelligently, such flexibility might lower costs and increase sustainabity through being able to reuse components of existing solutions to build radically different ones, instead of being either constrained to continue to use solutions that aren't optimal, or to incur the cost of discarding the current infrastructure. Since the only thing certain about the future is that it will contain disruption, this flexibility is critical to ensuring the sustainability and therefore cost efficiency of any energy development project.

A functional modeling approach enables key functions like storage, or transmission, to be virtualized. That is, it enables functions to be abstracted from any specific implementation so that they are portable properties of specific functional components which interact through well-defined interfaces. This approach not only modularizes designs by separating them into different physical components will well-defined interfaces, but it also modularizes designs by separating them into different virtual components. In software for example, this might entail separating software into modules.

Once problems are defined using a functional modeling approach, an adaptive problem-solving process might systematically consider all possible implementations for each module and assess the relative fitness of each, in order to optimize outcomes. General Collective Intelligence is intended to collectively reason in a coherent way in order to create such an adaptive problemsolving process. Through enabling groups to coherently reason in terms of these functional models, GCI is proposed here to gain the potential capacity to more reliably converge on the optimal solution, regardless of the number of choices, and to more rapidly adjust that choice according to the information and library of reasoning processes available from the entire group [12]. Where Tesla advocated for alternating current transmission, and Edison advocated for direct current, a GCI based smart solution might choose the best transmission method for each specific connection, and might be flexible enough to change that choice on the fly. General collective intelligence is also intended to remove the barriers to orchestrating massive interdisciplinary cooperation where required to develop such solutions. Rather than requiring a single entity to invest a lot of capital, which that entity might reliably do only if that solution aligned with their individual interests, GCI might enable a very large number of individuals to invest a much smaller effort, and a much wider number of other resources, which they might reliably be 
incentivized to do by solutions that create sufficient value through this cooperation.

\section{Components of a Design Approach Based on Human-Centric Functional Modeling and Leveraging General Collective Intelligence}

The Human-Centric Functional Modeling approach discussed in this paper was used to define a Functional Modeling Framework (FMF) [13] for representing organisms as a hierarchy of adaptive processes in different domains, including cognition. All of these models mimic the adaptive processes through which living organisms demonstrate a stable ability to converge on more optimal solutions in each problem-solving domain. The model of collective cognition (General Collective Intelligence) discussed in this paper replicates nature's solution of individual cognition by defining GCI as an adaptive problem-solving process operating in the domain of the collective cognition.

Creating a collaborative development process that leverages general collective intelligence to orchestrate development requires a cognitive model of the design and development processes that the GCI can manipulate through the above adaptive processes.

Development is suggested here to be closed in the sense that the problem as well as potential solution approaches have both already been defined. This is differentiated from design which is proposed to be open-ended in having the capacity to choose different definitions of the problem, as well as having the capacity to choose radically different approaches to the solution. Functional modeling of the open-ended design process is not explored here.

The adaptive processes for changing the development process, may be used, for example, to balance between development methodologies (e.g. waterfall) suited for projects with known requirements, and development methodologies (e.g. Agile) suited for projects with unknown requirements. The specific functions to be developed in either case must be determined through functional decomposition.

Together, the different adaptive domains are proposed to enable the development process to navigate a greater region of the entire solution space so that optimal solutions are accessible, and are proposed to reliably converge on those optimal solutions so that developing solutions with significantly greater impact on outcomes is reliably achievable.

In addition to modeling the functions of the development process, along with the necessary adaptive, and cooperative processes required for a GCI based approach to development, it is also necessary to define functional models of the solutions themselves so that these GCI based development processes have inputs to operate on.

In addition to GCI based adaptation in the solution development process, GCI based adaptation might also be introduced to every other process in the product or service life-cycle, from research and design, to recycling.

\section{Human-Centric Functional Modeling and General Collective Intelligence in Development vs in Design}

As discussed, a number of challenges with maximizing any collective outcome exist in the development process without GCI, one being that the owner of the process is free to align the process with their interests so that vendors with better implementations may be barred from participating. If optimal solutions are barred, maximizing any collective outcome, such as sustainability, might not be reliably achievable. In development, the approach to human-centric functional modeling and the GCI model discussed in this paper aim to enable groups of vendors and services providers to self-assemble their offerings into composite solutions with the capacity to maximize collective outcomes. This is a separate problem from the case of design, in which functional modeling and GCI aim to enable groups to self-assemble their concepts into the optimal definition of the design problem. 
As with any other approach to functional modeling, this approach defines a functional model for a class of solution and then uses functional decomposition to break the class of solution down into a number of functional components. The difference with this approach is defining functional models that are human-centric in being dependent only on the functions that can be perceived within innate human awareness, rather than being dependent on any implementation that might make assumptions that are not shared. This human-centric approach is part of applying the principles of decentralized cooperation. The difference with this approach is also using a model of General Collective Intelligence to orchestrate cooperation according to these principles, including removing the barriers to massive collaboration by enabling anyone to replace any functional model of a component, to replace any implementation of any functional model, or to replace anything else (including the entire system), with any alternative that is more fit at achieving the targeted goals. As an example, consider a solution to have a number of functional components as represented by the blue squares in the diagram below.

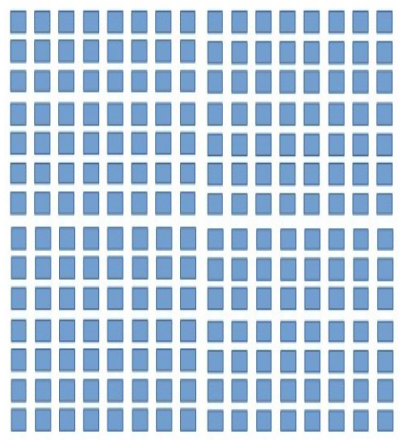

Figure 1. Functional components involved in modular solar energy solution.

In order to create a complete solution on their own, any product or services provider would potentially have to implement all of these functionalities, or find an implementation of the missing functionality that was compatible with their approach. Having done so they would also have to ensure deployment at scale so there are enough users to ensure implementing all the functionality required to achieve their goals is economically feasible. However, through collectively intelligent cooperation, each initiative could significantly reduce its work by limiting itself to having to develop only a restricted set of functionality as represented by the yellow squares below.

Figure 2. Functional components in one solar energy Product or Service.

The goal of orchestrating such cooperation is not building all this functionality. Instead it's to define the functions needed, and to identify where these functions already exist in each prospective provider's products and services, so that the problems and solutions can be matched together. Or alternatively, to coordinate with prospective partners who are funding initiatives to build such functionality, so that rather than them funding the implementation of all functional components and having a higher likelihood of not being successful at implementing any, they might cooperate with projects that have already succeeded in that implementation. Through this cooperation each project can agree to fund the development of some functionality, and another cooperating project can agree to fund other functionality, so that together there is a higher likelihood of being successful at all. By sticking to the activities each party can do most effectively, and by increasing the number of deployments to that required by the entire group of cooperating parties, through this cooperation all parties might multiply their impact on their targeted goals. 


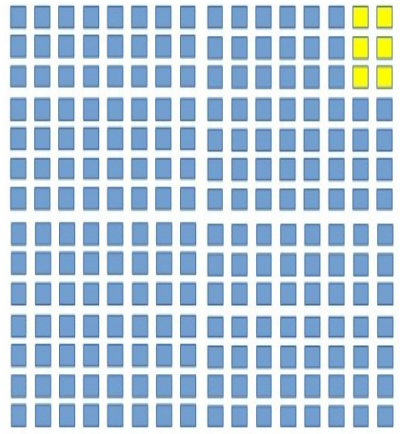

Figure 3. Map the Functional components in each vendor or project's product or service to the overall problem.

Creating functional models of each organization's offerings having that functionality, and defining general processes for assembling that

functionality, enables algorithms to be defined to computationally find optimal matches between problems and solutions at orders of magnitude greater speed and scale.

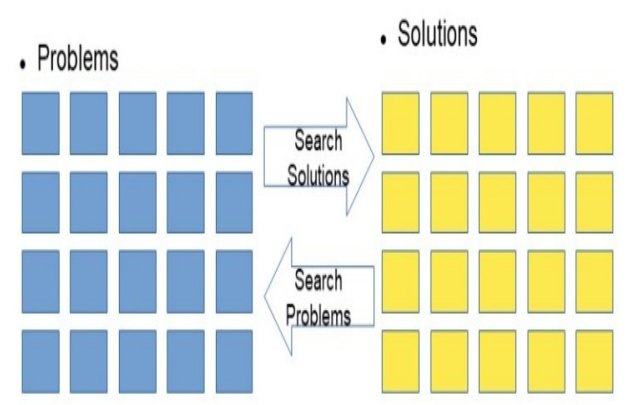

Figure 4. Algorithmically match requirements (development problems) to existing solution components.

In this human-centric approach to functional modeling of virtual or physical processes, each function a solution is required to have is represented in terms of an input, an output, a context of execution, and an outcome related to that output. In virtual processes the context of execution represents all the information that the output is dependent on that is not part of the input, such as configuration parameters. This modeling is human-centric in that the inputs, outputs, and context are concepts or sets of concepts that are defined semantically.

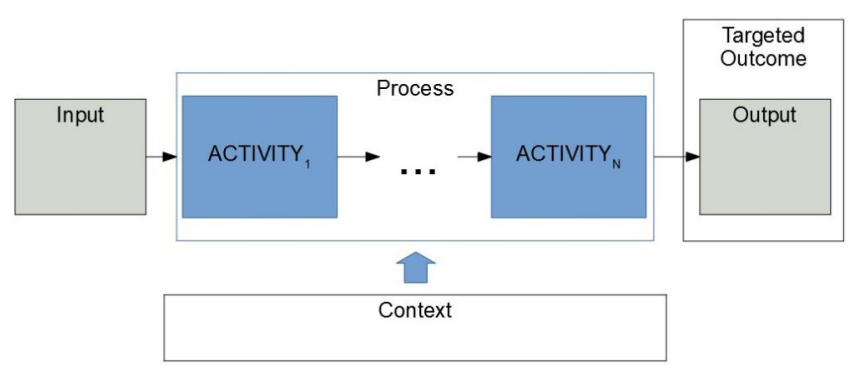

Figure 5. Functional modeling of functionality, processes, and their context of execution.

Processes are defined here as functions that can receive input multiple times within the same instance of execution.

\section{Findings}

As detailed in table 3, the research finding suggest that uncertainties in renewable energy solution research and development are a significant source of innovation, and that the combination of functional modeling and General Collective Intelligence can significantly increase capacity to innovate in these areas.

Table 2. Research Findings.

\begin{tabular}{|c|c|}
\hline Research Question & Findings \\
\hline $\begin{array}{l}\text { 1. What uncertainty is } \\
\text { there in which } \\
\text { outcomes should be } \\
\text { optimally targeted by } \\
\text { renewable energy } \\
\text { programs? }\end{array}$ & $\begin{array}{l}\text { 1. There is } \\
\text { significant } \\
\text { uncertainty. } \\
\text { However, that } \\
\text { uncertainty might } \\
\text { not be visible } \\
\text { within what } \\
\text { organizational } \\
\text { policies allow. }\end{array}$ \\
\hline $\begin{array}{l}\text { 2. What measures } \\
\text { might be used to } \\
\text { manage uncertainty in } \\
\text { which outcomes } \\
\text { should be optimally } \\
\text { targeted by renewable } \\
\text { energy programs? }\end{array}$ & $\begin{array}{l}\text { 2. The uncertainty } \\
\text { might be managed } \\
\text { through using GCI } \\
\text { based approaches } \\
\text { to increase } \\
\text { flexibility. }\end{array}$ \\
\hline $\begin{array}{l}\text { 3. Can decomposing } \\
\text { renewable energy } \\
\text { solutions into common }\end{array}$ & $\begin{array}{l}\text { 3. The answer } \\
\text { appears to be yes } \\
\text { pending }\end{array}$ \\
\hline
\end{tabular}




\begin{tabular}{ll}
\hline functional & experimental \\
components, and using & confirmation. \\
General Collective & \\
Intelligence to & \\
adaptively problem & \\
solve through the \\
entire business life- \\
cycle of renewable \\
energy solutions be \\
used to significantly \\
increase any outcome \\
targeted by renewable \\
energy program?
\end{tabular}

\section{Research Limitations}

Though models of a number of proposed GCI solutions have been defined in agriculture, health care, and other fields, and though conceptual case studies of these solutions have demonstrated the potential for the exponential increase in impact on outcomes as suggested might be achievable in this paper, GCI has not yet been implemented. As a consequence, many details inevitably remain to be clarified.

Furthermore, as described elsewhere [14] GCI is a complex system that must likely in effect be grown through initiating a self-assembling process that adapts in any way required to maximize collective outcomes rather than being developed in a top-down way that can become tightly coupled with centralized interests. Defining a simple functional model of GCI alone is not sufficient to implement GCI. An understanding of the self-reinforcing networks of cooperation and hierarchy of their deployment that is required [15], an understanding of the application of GCI to the customization of products and services deployed in those networks [10], an understanding of the platform required to execute processes with a GCI [16], as well as an understanding of the application of GCI to research, design, manufacturing, and all the other processes in the business life-cycle might be required [17], [18], [19]. In the same way that defining a simple functional model of the human system as containing a heart to pump blood, lungs to oxygenate blood and remove carbon dioxide, as well as containing other functional components is not sufficient to clone a human being. However, the process of understanding how to implement a GCI must begin with an understanding of the functional components required.

\section{Practical Implications}

A large team of approximately fifty engineering interns at the University of Nairobi were engaged in helping to elaborate the concept of a smart renewable energy solution called the SmartGrid. Though this design has not yet been implemented, such a design might serve as a reference for the renewable energy program in the proposed Collective Intelligence based Program to Accelerate Achievement of the Sustainable Development Goals (CIPAA-SDGs). In any case, the exercise was useful in examining how a modular and GCI based approach might better address the renewable energy challenges unique to Kenya.

\subsection{Overview of Proposed Reference Collective Intelligence Based Solar Energy Solution}

The principles of modularization to enable cooperation to be scaled in a decentralized way are elaborated in more detail elsewhere [16], but with regards to renewable energy, their most important implications are suggested here to be that a solution must be easily installed, expanded, and maintained, and that all these activities must be achievable in terms of user-centric modules that require little expertise and no specialized tools.

\section{Functional Components of SmartGrid}

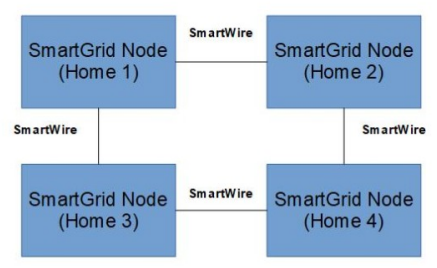

Figure 6. Modular nodes in a SmartGrid renewable energy solution. 
In the solution envisioned, home owners might purchase a modular solar energy solution off-theshelf and install it on their own. The home owner might then add modules to increase the power generation, power handling, storage, or other capacities of the solution. The home owner might also plug this solution into smart grid infrastructure provided by the program, so that they might in essence cooperate to become a local utility, cooperating to create added capacity to store power in times of plenty, and cooperating to share power in times of need. This solution is proposed to consist of the following components (table 3).

Table 3. Solution Components.

\section{Component Description}

\begin{tabular}{|l|l|}
\hline Smartwire & $\begin{array}{l}\text { A multi-purpose pluggable } \\
\text { wiring system that enables rapid } \\
\text { and secure connection. }\end{array}$ \\
\hline Smartgrid & $\begin{array}{l}\text { Enables individuals to set the } \\
\text { policies of their participation so } \\
\text { that private agents in a repository } \\
\text { of the user's sole control may act } \\
\text { on their behalf in dynamically } \\
\text { forming the grid. }\end{array}$ \\
\hline $\begin{array}{l}\text { SmartSolarpa } \\
\text { nel }\end{array}$ & $\begin{array}{l}\text { A modular, expandable system of } \\
\text { solar panels that maximizes } \\
\text { production by enabling energy to } \\
\text { be harnessed across a wider } \\
\text { range of the electromagnetic } \\
\text { spectrum, and that enables other } \\
\text { functions to be accommodated. }\end{array}$ \\
\hline Smartstorage & $\begin{array}{l}\text { A modular, expandable system of } \\
\text { storage that permits a range of } \\
\text { storage technologies to be used. }\end{array}$ \\
\hline SmartPower & $\begin{array}{l}\text { A modular, expandable system } \\
\text { for managing increased power } \\
\text { output from larger solar arrays. }\end{array}$ \\
\hline $\begin{array}{l}\text { Peer-to-Peer } \\
\text { (P2PSF) }\end{array}$ & $\begin{array}{l}\text { A decentralized system for } \\
\text { managing identities, applications, } \\
\text { and data on which the } \\
\text { applications managing the } \\
\text { smartgrid, smartwire, and other } \\
\text { IoT solutions are deployed. }\end{array}$ \\
\hline Fabrion
\end{tabular}

A conceptual model of the nodes in the smartgrid is depicted below showing the functional components of each smartgrid node:

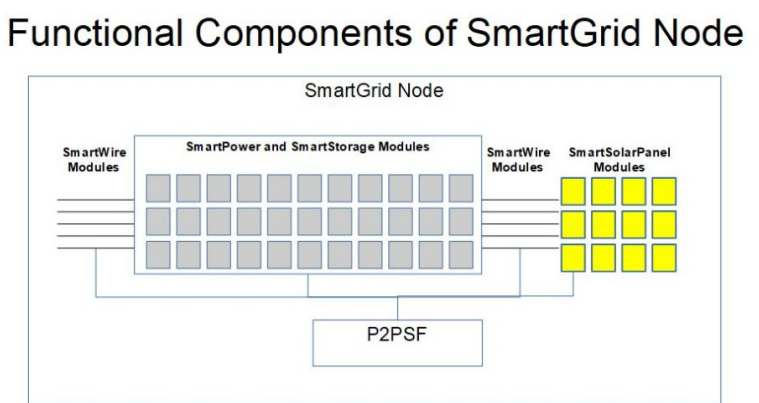

Figure 7. Proposed components of a smartgrid node. 
The smartpower input module, smart storage module, and smartpower output module form a larger module that. may be stacked into connected assemblies. Smartwire is also provided as infrastructure for the smartgrid. This infrastructure uses existing utility poles (or is placed underground) to permit users to connect themselves to the smartgrid.

Infrastructure Components of SmartGrid

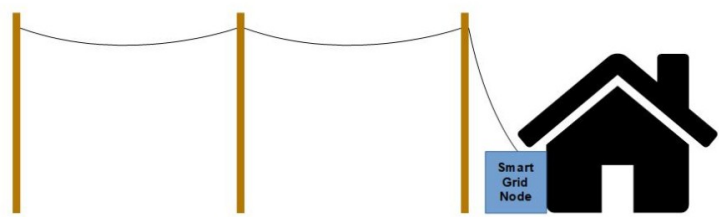

Figure 8. SmartGrid node (blue square) connected to the power grid.

The smartwire connection to the home is proposed to have the capacity to be connected or disconnected by the user. The reference concept was designed without a formal exercise in functional decomposition, which is yet to be performed. However, the functions of these functional components can always change as the requirements are elaborated. Without formal functional decomposition such a change is even more likely to be the case.

\subsection{Benefits and Impact of a Proposed Reference Collective Intelligence Based Solar Energy Solution}

The reference design concept was originally created with a particular intended deployment in mind, and that was in rural schools in Kenya as part of the large scale deployment of learning technology. Some expected requirements and their benefits for that application are listed below. In the proposed CIPAA-SDGs program these requirements are intended to be adapted for residential deployment of the SmartGrid in the Caribbean and elsewhere:

Table 4. Proposed Solution Benefits. 


\begin{tabular}{|l|l|}
\hline Ease of & $\begin{array}{l}\text { More power can be added into the } \\
\text { system whenever power demands } \\
\text { rises. In a situation where more } \\
\text { power is required to be generated, } \\
\text { the solar panels will be added onto } \\
\text { the existing solar modules to } \\
\text { increase the input to the battery } \\
\text { modules. The output power control } \\
\text { module should have the capacity to } \\
\text { handle 1-4 times the capacity of a } \\
\text { single battery to accommodate any } \\
\text { future expansion in power modules } \\
\text { just in case the consumption needs } \\
\text { will expand, and it should allow } \\
\text { addition of extra battery modules to } \\
\text { cover the rising needs for power } \\
\text { while supplying power without } \\
\text { strain. }\end{array}$ \\
\hline $\begin{array}{l}\text { Integrates } \\
\text { into Power } \\
\text { Grid }\end{array}$ & $\begin{array}{l}\text { To ensure power is available under } \\
\text { any conditions, it is essential to } \\
\text { have a large enough solar power } \\
\text { generating capacity and enough } \\
\text { battery storage capacity to bridge } \\
\text { periods of low sunshine. It is also } \\
\text { important to integrate into the } \\
\text { power grid where power } \\
\text { infrastructure exists so that power } \\
\text { can be drawn from it if necessary. } \\
\text { However when new solar } \\
\text { generating capacity is added, } \\
\text { perhaps in anticipation of additional } \\
\text { students or additional equipment, } \\
\text { there may actually be excess } \\
\text { capacity. To ensure that newly } \\
\text { added solar power capacity can pay } \\
\text { for itself while demand is still } \\
\text { growing; the solution has the } \\
\text { capability to add power back to the } \\
\text { grid without any additional costly } \\
\text { configuration. }\end{array}$ \\
$\begin{array}{l}\text { There will be a different module } \\
\text { that will be used to feed back any } \\
\text { excess power to the national grid } \\
\text { during peak generation periods and } \\
\text { when less power is needed for } \\
\text { consumption to gather for power } \\
\text { requirements during low sun } \\
\text { seasons whenever that happens and }\end{array}$ \\
\hline
\end{tabular}

ensure a continuity in power supply
and hence ensuring a smooth,
efficient, reliable and a long lasting
power supply solution and promote
a smooth learning process for
students.




\begin{tabular}{|l|l|}
\hline Simplicity & $\begin{array}{l}\text { Modular design uses a simpler } \\
\text { approach in installation in that } \\
\text { anyone can add or remove more } \\
\text { modules into the system without } \\
\text { any need of specialized technical } \\
\text { knowledge or tools, by just } \\
\text { plugging in or out of additional } \\
\text { modules without interfering on the } \\
\text { operation of the system apart from } \\
\text { just increasing or decreasing the } \\
\text { power output of the system } \\
\text { appropriately. }\end{array}$ \\
\hline Flexibility & $\begin{array}{l}\text { The design offers flexibility and } \\
\text { efficiency in power supply for the } \\
\text { learning process in remote regions } \\
\text { where electricity supply has been } \\
\text { challenging. For a classroom of } 25 \\
\text { students the power generation } \\
\text { capacity required to supply } \\
\text { considering the charging } \\
\text { requirements of the } \\
\text { EDUCATIONAL COMPUTER } \\
\text { alternative alone is estimated to be } \\
\text { 10Watts. This is equivalent to one } \\
\text { unit of the solution. The power } \\
\text { generation capacity required to } \\
\text { supply additional incidental needs } \\
\text { such as charging the teacher's cell } \\
\text { phone, running audio visual } \\
\text { equipment, or supplying internet } \\
\text { connectivity is estimated to be an } \\
\text { additional 220W amounting to a } \\
\text { second unit of the solution. The } \\
\text { solution allows an unlimited } \\
\text { number of units to be added to } \\
\text { reach a power generation capability } \\
\text { from 230W to (unlimited), with a } \\
\text { maximum current of 6A through a } \\
\text { single outlet. }\end{array}$ \\
\hline $\begin{array}{l}\text { and } \\
\text { and }\end{array}$ \\
\hline
\end{tabular}

\begin{tabular}{|c|c|}
\hline $\begin{array}{l}\text { Where } \\
\text { Solar } \\
\text { Power } \\
\text { Solution is } \\
\text { the Most } \\
\text { Viable Path } \\
\text { to } \\
\text { Electrificati } \\
\text { on }\end{array}$ & $\begin{array}{l}\text { Instilling technological } \\
\text { preparedness for the jobs of the } \\
\text { future has been identified as a key } \\
\text { goal for Kenya's schools. Yet a } \\
\text { great many of Kenya's schools, } \\
\text { particularly rural primary schools, } \\
\text { are without electricity. Without } \\
\text { electricity there is no possibility of } \\
\text { providing access through the } \\
\text { internet to the entire world of } \\
\text { educational content available on the } \\
\text { web to benefit Kenyan students. } \\
\text { Not to mention that whatever laptop } \\
\text { solution is chosen, there must be } \\
\text { means to charge it. }\end{array}$ \\
\hline $\begin{array}{l}\text { Cost } \\
\text { Effectivene } \\
\text { ss }\end{array}$ & $\begin{array}{l}\text { With components specially } \\
\text { manufactured for Nobeah this } \\
\text { solution is expected to be } \\
\text { significantly more cost effective } \\
\text { than any competing solutions. } \\
\text { When considering the added } \\
\text { features such as security and } \\
\text { modularity that have been designed } \\
\text { into the solution to make it ideally } \\
\text { suited to deployment in Kenya's } \\
\text { schools, the FreeSunPower solution } \\
\text { provides unbeatable value. }\end{array}$ \\
\hline Modularity & $\begin{array}{l}\text { The units of the solution are } \\
\text { completely modular so that power } \\
\text { generation capacity, additional } \\
\text { storage capacity, or additional } \\
\text { connectivity options can be added } \\
\text { by completely non-technical staff } \\
\text { with no possibility of either } \\
\text { overloading the system or of } \\
\text { suffering electrical shock during } \\
\text { installation or upgrade. These units } \\
\text { give alerts when they are not } \\
\text { functioning properly. }\end{array}$ \\
\hline
\end{tabular}




\begin{tabular}{|c|c|}
\hline Security & $\begin{array}{l}\text { Rural schools may lack security } \\
\text { and solar panel solutions are prime } \\
\text { targets of theft. To prevent such } \\
\text { theft Nobeah's reference design has } \\
\text { an integrated cable lock system that } \\
\text { enables the modules to be quickly } \\
\text { locked into place and the entire } \\
\text { assembly secured against any } \\
\text { immovable object nearby, whether } \\
\text { it be a beam, a tree, or even a } \\
\text { specially installed post set into the } \\
\text { ground with a concrete footing. To } \\
\text { secure the solar panels themselves } \\
\text { the name of the customer along } \\
\text { with a serial number are etched into } \\
\text { the glass of the panels. Any transfer } \\
\text { of panels from one owner to another } \\
\text { can be registered online as well. } \\
\text { These identifying measures ensure } \\
\text { that the community can clearly } \\
\text { identify panels as belonging to their } \\
\text { rightful owners so the community } \\
\text { can contribute to ensuring their } \\
\text { safety }\end{array}$ \\
\hline $\begin{array}{l}\text { Feasibility } \\
\text { and } \\
\text { Advantages } \\
\text { of Modular } \\
\text { Design }\end{array}$ & $\begin{array}{l}\text { The design is based on plug and } \\
\text { play principle that will ensure that } \\
\text { anyone can add more modules } \\
\text { manually onto the system or remove } \\
\text { any extra module from the system } \\
\text { easily without any call for a } \\
\text { specialist to do the process by just } \\
\text { plugging the modules into the } \\
\text { existing ones to meet the demand. } \\
\text { We are interested in developing a } \\
\text { system that anyone can use even } \\
\text { without any special skill or } \\
\text { knowledge regarding installation. }\end{array}$ \\
\hline
\end{tabular}

Such modules might have an integrated security

\section{Acknowledgements.}

Thanks to Julian Talev for countless discussions on the topic.

\section{References}

system that requires a cell phone or $3 \mathrm{G}$ modem to be plugged in to act as an internet access point so that the system can "phone home" to authenticate itself as being used by its rightful owner. Where such connectivity is not available the system might produce a request code to be given to the service desk of the authorized provider to produce a response code that is entered into the device to authenticate it. By leaving this "phone home" functionality to be implemented by a separately purchased Smartphone or 3/4/5 G modem, the system might greatly reduces costs.

\section{Conclusions}

In that nature has developed life as a set of adaptive problem-solving processes that sustainably solve problems in a wide range of domains, nature already has solutions it has in some cases proven over billions of years, that can be abstracted to address potentially any human problems, including the problem of clean energy generation. Rather than seeing renewable energy as a problem of increasing solar energy deployment, or increasing geothermal, or wind energy deployment, the biggest opportunity might come with seeing it as a problem of optimizing the aspects of collective well-being that fall into the energy domain. If well-being is defined as "fitness to execute all functions", and if nature's solution to achieve it is to coherently optimize outcomes across all of an organism's functions, then doing so requires some optimization function. Through use of functional modeling to represent such functions so that optimization is possible, and through use of GCI to actually achieve that optimization, nature's solution might be leveraged in renewable energy as well.

1 Pre-print: Williams, A. E. (2020, May 15). Use of Human-Centric Functional modelling to Maximize Convergence in Integrative Research. https://doi.org/10.31730/osf.io/jv6h8

2 Journal article: Woolley, Anita Williams; Chabris, Christopher F.; Pentland, Alex; Hashmi, Nada; Malone, Thomas W. (29 October 2010). "Evidence for a Collective 
Intelligence Factor in the Performance of Human Groups". Science. 330 (6004): 686688. Bibcode:2010Sci...330..686W. doi:10.1126/science.1193147. PMID 20929725. S2CID 74579.

3 Journal article: Krafft, P.M. (2019), A Simple Computational Theory of General Collective Intelligence. Top Cogn Sci, 11: 374-392. https://doi.org/10.1111/tops.12341.

4 Book: Malone, T. W. (2018). Superminds: The surprising power of people and computers thinking together.

5 Pre-print: Williams, A. E. (2020, December 2). General Collective Intelligence vs the Innate Collective Intelligence Factor. https://doi.org/10.31730/osf.io/kp3x8

6 Conference: The Relationship Between Collective Intelligence and One Model of General Collective Intelligence, Andy E. Williams, Computational Collective Intelligence, 11th International Conference, ICCCI 2019, Hendaye, France, September 4-6, 2019, Proceedings, Part II, Pages 589600

7 Pre-print: Andy E. Williams, General Collective Intelligence and the Constraints to Group Decision-Making, DOI: 10.31234/ osf.io/6gten

8 Pre-print: Andy E. Williams, The Need for General Collective Intelligence in Addressing the Sustainable Development Goals, under review, https://www.researchsquare.com/article/rs-18022/v1

9 Pre-print: Williams, A. E. (2020, December 1). General Collective Intelligence as the Emerging Paradigm in Human-Centric Design for Sustainability. https://doi.org/10.31730/osf.io/c4xgs

10 Pre-print: Williams, A. E. (n.d.). Individualization of Products and Services with Artificial General Intelligence and General Collective Intelligence. Retrieved from osf.io/preprints/africarxiv/gd5mt

11 Pre-print: Williams, A. E. (2020, April 30). The Collective Intelligence based Program to Accelerate Achievement of the Sustainable Development Goals as a Case Study for Collectively Intelligent Program Design. https://doi.org/10.31235/osf.io/r2dxq
12 Pre-print: Williams, A. E. (2020, August 19). Defining Functional Models of Collective Intelligence Solutions to Create a Library a General Collective Intelligence can use to Increase General Problem Solving Ability. https://doi.org/10.31730/osf.io/q75rv

13 Pre-print: Williams, A. E. (2020, April 16). A Human-Centric Functional Modeling Framework for Defining and Comparing Models of Consciousness and Cognition. https://doi.org/10.31234/osf.io/94gw3

14 Pre-print: Williams, A. E. (2020, November 11). General Collective Intelligence and the Transition to Collective Super-Intelligence. https://doi.org/10.31730/osf.io/tacyq

15 Pre-print: Williams, A. E. (2020, December 16). Discovering and Implementing Self-Sustaining Networks of Cooperation with General Collective Intelligence. https://doi.org/10.31730/osf.io/safxk

16 Pre-print: Williams, A. E. (n.d.). The Peer to Peer Social Fabric as a Platform for General Collective Intelligence. Retrieved from osf.io/preprints/africarxiv/qbxfr

17 Pre-print: Williams, A. E. (2020, December 18). Increasing Discovery in Research, Design, and Other Processes with Artificial General Intelligence and General Collective https://doi.org/10.31730/osf.io/gz385

Intelligence.

18 Pre-print: Williams, A. E. (2020, August 17). General Collective Intelligence as Biomimicry of Nature's Design and Manufacturing Processes. https://doi.org/10.31730/osf.io/92rqx

19 Pre-print: Williams, A. E. (2020, August 17). The Necessity of General Collective Intelligence Driven Processes in Achieving Pervasive Manufacturing. 